\title{
Os Sentimentos e o Fantasiar em Crianças que Aguardam Cirurgia
}

\author{
Paula Moraes Pfeifer* \& Alberto Manuel Quintana \\ Universidade Federal de Santa Maria, Santa Maria, RS, Brasil
}

\begin{abstract}
RESUMO - O processo cirúrgico carrega a ideia de agressão, passividade e mobiliza angústias impensáveis. Este estudo qualitativo, descritivo e exploratório investigou as fantasias presentes em crianças no dia anterior à cirurgia. Incluíramse sete crianças, de ambos os sexos, com idade de cinco a doze anos, internadas para realização de cirurgia em 2014. Utilizou-se como instrumentos lúdicos A Hora do Jogo e o Teste das Fábulas e os dados passaram por análise de conteúdo. Os participantes expressaram a percepção de si enquanto defeituosos e sentimentos de fragilidade, desamparo e diversos medos, bem como fantasias atemorizantes e elaborativas. Concluiu-se que a fantasia manteve seu papel paradoxal: mesmo se constituindo em uma defesa regressiva, revelou-se uma estrutura protetora, auxiliando a atribuir sentido à experiência cirúrgica.
\end{abstract}

PALAVRAS-CHAVE: psicanálise, psicologia, fantasias, cirurgia infantil

\section{Children's Feelings and Fantasies While Awaiting Surgery}

\begin{abstract}
Surgical procedures convey the idea of aggression and passivity and cause unimaginable anguish. This qualitative, descriptive and exploratory study investigated the use of fantasy by children the day before surgery. Seven children, both sexes and aged five to twelve, who were admitted for surgery in 2014 were included in the study. The instruments used in this study were Play Time and Fables Test. Content analysis was used to explore the data. The participants considered themselves as defective, possessed feelings of fragility and helplessness, and had many fears and frightening elaborative fantasies. It was concluded that fantasies maintained a paradoxical role: even if constituting a regressive defense, they proved to be protective structures, helping to make sense of the surgical experience.
\end{abstract}

KEYWORDS: psychoanalysis, psychology, fantasies, pediatric surgery

\section{INTRODUÇÃO}

A cirurgia se caracteriza por ser um procedimento invasivo, no qual envolve a realização de exames incômodos e desperta vários sentimentos e mal-estares, por colocar a criança em contato com um mundo, até então, desconhecido (DeMaso \& Snell, 2013; Garanhani \& Valle, 2012; Mikowski, 2008). A indicação cirúrgica geralmente é vivenciada pela criança como uma ameaça à sua integridade corporal $\mathrm{e}$ emocional. A cirurgia carrega em si a ideia ambivalente de que, para curar e recuperar a saúde, esta deve passar por procedimentos agressivos e dolorosos. Independentemente da idade da criança, do tipo ou porte da cirurgia e do fato dela já ter vivenciado procedimento semelhante, o processo cirúrgico pode mobilizar sentimentos e fantasias variados
(DeMaso \& Snell, 2013; Garanhani \& Valle, 2012; Goidanich \& Guzzo, 2012; Velázquez et al., 2005).

A cirurgia infantil possui a peculiaridade de ser uma experiência em que não há a possibilidade da criança escolher ou expressar seus desejos e temores em relação a ela. Esse fato decorre, principalmente, da crença cultural de que as crianças não são capazes de compreender a complexidade de um processo cirúrgico. Além disso, muitas vezes, essa crença vem acompanhada pela dificuldade dos adultos em lidar com as angústias mobilizadas pela indicação cirúrgica e, assim, acabam evitando o assunto ou enganando a criança. Entretanto, contrariamente a essas duas situações, a criança tem grande capacidade de observação e percebe que algo

*E-mail: paulabmpfeifer@gmail.com 
diferente ocorre. Quando os pais tentam esconder ou evitam falar sobre a cirurgia com a criança, acabam intensificando seus medos e angústias, podendo alimentar fantasias atemorizantes e acionar medos primitivos infantis (DeMaso \& Snell, 2013; Finkel \& Espíndola 2008; Garanhani \& Valle, 2012; Hearst, 2009; Lepri, 2008; Mikowski, 2008).

Existe, no hospital, a crença difundida pelo senso comum e também alguns trabalhos, de que as fantasias, por serem defesas primitivas, dificultariam o período pós-operatório (Costa, Silva, \& Lima, 2012; Martínez, León, Rodríguez, \& Moctezuma, 2010; Prudenciatti et al., 2013). Esses autores defendem a ideia de que elas reforçariam quadros de angústia e ansiedade frente à cirurgia. Entretanto, dentro de um referencial teórico psicanalítico, é atribuído à fantasia um papel paradoxal. Assim, mesmo a fantasia sendo uma defesa regressiva, ela é considerada uma estrutura protetora, que auxilia na sublimação, constituindo-se em defesa momentânea à castração real imposta pelo ato cirúrgico (Abel, 2011; Araújo, 2013).

Lepri (2008) chamou a atenção, em seu estudo, para o duplo papel que a fantasia exerce na situação de adoecimento e da necessidade da realização de uma cirurgia. De acordo com ela, a cirurgia se configuraria, para a criança, em uma ameaça real de desintegração e, consequentemente, suscitaria medos infantis primitivos. Nesse contexto, a fantasia funcionaria tanto como uma representante das pulsões, quanto como uma defesa e se mostraria um recurso necessário à integridade do ego, para que a criança consiga lidar com uma realidade desconhecida e tentar atribuir algum sentido a ela. Frente a esses fatos, questiona-se: (1) O que sentem as crianças quando vão ser submetidas a uma cirurgia?; (2) Que fantasias estão presentes nesse processo?.

Portanto, levando em conta o caráter traumático, a passividade, todas as angústias e fantasias mobilizadas pelo evento cirúrgico e a necessidade da criança de se defender, este estudo se propôs a compreender, a partir de um referencial teórico psicanalítico, o que sentem as crianças frente à intervenção cirúrgica. Além disso, visou a identificar as fantasias presentes no momento que antecedia um procedimento cirúrgico.

\section{MÉTODO}

Tendo em vista a complexidade do estudo da temática saúde-doença no indivíduo - um ser social, histórico e cultural -, optou-se pela realização de um estudo com delineamento qualitativo, descritivo e exploratório, utilizando-se a abordagem clínico-qualitativa. Esse método, de acordo com Turato (2003), é capaz de aprofundar a busca da compreensão de sentidos e significados atribuídos pelo homem nesse campo, proporcionando uma perspectiva holística e uma abordagem mais integral.

Foram incluídas, neste estudo, crianças de ambos os sexos, com idades de cinco a doze anos, internadas em unidade pediátrica de um hospital público do Rio Grande do Sul, para realização de cirurgia durante 2014. De acordo com o Estatuto da Criança e do Adolescente (ECA; Brasil, 1990), considera-se criança a pessoa até 12 anos de idade. Foram excluídas crianças que não estivessem conscientes e que não tinham condições de brincar.

Frequentou-se a secretaria do bloco cirúrgico durante as segundas e quartas-feiras, durante o período de abril a dezembro de 2014, para informar-se a respeito de quais crianças iriam para cirurgia. Tal procedimento era realizado nas terças e quintas-feiras pela manhã, posteriormente, era feito o contato com a equipe, verificando se o paciente tinha condições médicas para participar do estudo. A seguir, eram explicados os objetivos do estudo aos familiares e à criança e fazia-se o convite.

Foram entrevistadas todas as crianças que passariam por procedimentos cirúrgicos, que preenchiam os critérios de inclusão e que concordaram em participar do estudo. A amostra foi de sete participantes, estabelecida pelo critério de saturação. Dessa maneira, à medida em que os dados eram coletados, foram realizadas as transcrições e a análise do seu conteúdo. Verificou-se que, a partir do sexto participante, não surgiram dados novos, fato que também se manteve no sétimo. Assim, devido à repetição das informações coletadas, entendeu-se que não era relevante persistir na coleta e que um número excedente de participantes não acrescentaria muito ao estudo (Fontanella, Ricas, \& Turato, 2008). As principais características dos participantes estão descritas no Quadro 1.

Utilizaram-se como instrumentos A Hora do Jogo (HJ) e o Teste das fábulas (TF). A definição da utilização dessas ferramentas objetivou facilitar o acesso à expressão dos sentimentos, das percepções e das fantasias das crianças que realizariam cirurgias.

A HJ ou entrevista lúdica parte do pressuposto de que a criança, ao brincar, expressaria com maior facilidade seus pensamentos e sentimentos, que dificilmente conseguiria verbalizar. De acordo com Winnicott (1982/2008), é através do brincar que a criança conhece o mundo e aprende a se relacionar com ele, bem como começa a diferenciar as realidades interna e externa. Através dos jogos e das brincadeiras, a criança pode repetir uma situação traumática, vivenciada anteriormente de maneira passiva, como tentativa de dominar e atribuir significação a essa experiência (Freud, 1920/1996; Winnicott, 1982/2008). Tanto o brincar, quanto o fantasiar são motivados pelo desejo. Entretanto, no brincar, as forças motivadoras envolvem a realização de um desejo, já no fantasiar, essas são motivadas por desejos insatisfeitos, tentando corrigir uma realidade insatisfatória (Freud, 1908/1996). 
Quadro 1. Principais características dos participantes

\begin{tabular}{ll}
\hline Participante 1 & $\begin{array}{l}\text { Menino, } 12 \text { anos, filho mais velho. Mora com os pais e irmão. A família possui casa própria, renda média de cinco salários } \\
\text { mínimos. Primeira Cirurgia. Biópsia. }\end{array}$ \\
\hline Participante 2 & $\begin{array}{l}\text { Menina, } 11 \text { anos, filha mais nova. Mora com pais e irmã. A família possui casa própria, renda familiar média de dois } \\
\text { salários mínimos. Segunda Cirurgia. Colecistectomia. }\end{array}$ \\
\hline Participante 3 & $\begin{array}{l}\text { Menino, 9 anos, filho mais velho. Mora os pais, irmão e irmã. A família possui renda familiar média de seis salários } \\
\text { mínimos. Primeira Cirurgia. Apendicectomia. }\end{array}$ \\
\hline Participante 4 & $\begin{array}{l}\text { Menino, } 5 \text { anos, filho mais velho. Mora com mãe, padrasto e irmão. A família reside na zona rural, renda média de um e } \\
\text { meio salário mínimo. Primeira Cirurgia. Pieloplastia. }\end{array}$ \\
\hline Participante 5 & $\begin{array}{l}\text { Menino, 12 anos, filho mais novo. Mora com mãe adotiva, viúva, e irmão. A família possui casa própria, renda média de } \\
\text { quatro salários mínimos. Primeira Cirurgia. Fratura exposta no braço. }\end{array}$ \\
\hline Participante 6 & $\begin{array}{l}\text { Menino, } 6 \text { anos, filho único. Mora com os avós. A família possui casa própria, reside na zona rural, renda média de um } \\
\text { salário mínimo. Segunda Cirurgia. Hipospádia. }\end{array}$ \\
\hline Participante 7 & $\begin{array}{l}\text { Menina, } 8 \text { anos, filha mais nova. Mora com os pais e irmão. A família possui renda média de um e meio salário mínimo. } \\
\text { Primeira Cirurgia. Cisto branquial. }\end{array}$ \\
\hline
\end{tabular}

O material lúdico foi apresentado em uma caixa contendo materiais simples e básicos para facilitar o acesso à fantasia infantil, possuindo também materiais presentes no contexto hospitalar e cirúrgico. A única instrução oferecida à criança foi de que brincasse livremente a respeito do motivo de sua internação e não foi realizada nenhuma interpretação (Aberastury, 1972/1992).

O TF, neste estudo, foi utilizado como um recurso para estimular a expressão das fantasias e de conteúdos inconscientes mobilizados pela angústia suscitada pela iminência da realização de um procedimento cirúrgico. Ele é um teste projetivo, composto por dez estórias e com ilustrações adequadas a cada uma delas. As fábulas são finalizadas com uma pergunta, a qual a criança deve responder completando a estória (Cunha \& Nunes, 1993).

A aplicação dos instrumentos teve duração aproximada de uma hora. Iniciou-se pela HJ, técnica com quarenta e cinco minutos de duração, por ser menos ansiogênica. Posteriormente, foi realizado o TF, de quinze a vinte minutos de aplicação. Ambos os instrumentos foram aplicados em uma sala na unidade em que a criança se encontrava internada, proporcionando certa privacidade, mas também permitindo a realização de procedimentos aos quais poderia ser submetida, como, por exemplo, realização de exames e de medicações.

Finalizada a fase de coleta de dados, as informações recolhidas foram transcritas na íntegra. A análise dos dados foi realizada mediante a técnica de análise de conteúdo, descrita por Bardin (1977/2010). O TF também passou por análise de conteúdo, de forma a contemplar os objetivos desta pesquisa, levando em consideração que ela não almejava um diagnóstico.

As informações gravadas durante o período de coleta de dados foram transcritas na íntegra. Primeiramente, realizaram-se leituras flutuantes desse material, buscando uma impregnação dos dados coletados. A seguir, foram destacados os aspectos recorrentes do discurso, elaborandose, assim, categorias a posteriori e separando-as em unidades de registro (Bardin, 1977/2010). Depois, os dados foram interpretados a partir de um referencial teórico psicanalítico.

O projeto de pesquisa foi aprovado em 8 de abril de 2014, sob o número de registro CAAE 28759614.9.0000.5346. Em todas as etapas da pesquisa, foram considerados os preceitos éticos presentes na Resolução $\mathrm{n}^{\circ} 466$, de 12 de dezembro de 2012, do Conselho Nacional de Saúde (Brasil, 2012) e na Resolução 010/2012, do Conselho Federal de Psicologia (Conselho Federal de Psicologia, 2012).

\section{RESULTADOS}

A partir da análise dos dados coletados durante $\mathrm{HJ}$ e o $\mathrm{TF}$, emergiram as seguintes categorias: Os seres deformados; Fragilidade, desamparo e medo; A angústia de castração, a perda da onipotência e a ameaça de morte; Fantasias atemorizantes ou persecutórias; A identificação com o agressor e a ambivalência atribuída à figura do médico e Fantasias elaborativas ou criativas.

\section{Os Seres Deformados}

O corpo é constituído socialmente, isto é, a sociedade institui padrões de crenças, alimentação, forma, vestuário e daquilo que é desejável e aceitável dentre as classes sociais. Esses modelos acabam por interferir na composição da subjetividade dos sujeitos, já que é através do corpo que o bebê estabelece seus primeiros contatos com o mundo externo. A partir daí, é forjada a definição de imagem corporal, um conceito psicológico, singular a cada sujeito, pois está ligado à sua história e às suas representações de mundo (Dolto, 1984/2008; Ferreira, 2008; Torres-Oquendo \& Toro-Alfonso, 2012). Dolto (1984/2008) definiu a imagem corporal como a imagem inconsciente que o sujeito possui do seu corpo e a distinguiu do conceito de esquema corporal, que seria uma percepção neurobiológica consciente ou préconsciente comum a todos os indivíduos. 
Neste estudo, a partir da interpretação dos resultados, verificou-se que as crianças expressaram a percepção de sua imagem corporal enquanto possuidoras de uma falha, a ser corrigida através da cirurgia. Fato também constatado pelo trabalho de Finkel e Espíndola (2008). Percebeu-se, também, durante a aplicação da HJ, que os participantes utilizaram, comumente, as temáticas de brincar de médico, mecânico e marceneiro como forma de expressão de sua percepção acerca de si e do procedimento cirúrgico. Essas brincadeiras possuíam, em comum, a ideia da presença de uma deformação ou uma falha e a necessidade de conserto ou reparação. Assim, através da brincadeira, existiria o deslocamento de suas percepções e sentimentos de si para as coisas, isto é, os brinquedos, facilitando sua expressão. No contexto das brincadeiras realizadas durante $\mathrm{HJ}$, três participantes verbalizaram: "Está estragado. (fala mexendo nas rodas) Meu tio gosta muito de motos. Ai, ele se acidentou. Caiu da moto. Estragou toda a moto e ele teve que levar pra arrumar" (HJ, P.4, Menino, 5 anos); "De marcenaria. (...) A gente vai consertar uma carroça. Daí, lá a gente pinta a carroça" (HJ, P.1, Menino, 12 anos); "Esse aqui todo mundo acha feio. Ele até que é bonitinho no desenho" (HJ, P3, Menino, 9 anos).

\section{Fragilidade, Desamparo e Medo}

Percebeu-se, através da análise desse material, que a iminência de cirurgia mobilizava elevada angústia em alguns participantes, que se mostravam mais irritadiços, apresentando dificuldade de concentração. Todos os participantes verbalizaram de maneira recorrente sentimentos de fragilidade, desamparo, solidão, tristeza, confusão e medos da dor, do desconhecido, de sofrerem mutilações e da morte. Esses sentimentos estão ilustrados na verbalização dos participantes durante $\mathrm{HJ}$ e o TF:

É que eu vou ter que me operar. (...) Eu tô... eu tô com um pouquinho de medo. Porque eu nunca... (HJ, P.2, Menina, 11 anos)

Nervoso. (...) Tô confuso. Eu não sei. (ri quase como suspirando ansioso) Aham, senão eu me lembro. Daí, eu fico com medo. (HJ, P.3, Menino, 9 anos)

Porque o papai e a mamãe dele sobem; daí, deixam ele sozinho lá embaixo, para ele subir sozinho. (...) Porque se ele... ele só sabia voar um pouquinho e se ele voasse, ele ia cair no chão e se machucar. (TF, P.7, Menina, 9 anos)

Apesar de todo o avanço tecnológico da medicina nas últimas décadas, o processo cirúrgico se constitui em um momento de crise. Ele coloca a criança em contato com as perdas ocasionadas pelo adoecimento indesejado, procedimentos dolorosos e desagradáveis e a confronta com o desconhecido.

Independentemente da idade da criança, de já ter vivenciado alguma cirurgia anteriormente ou da complexidade desse procedimento, a agressividade e o desconhecimento do processo cirúrgico colocam-na em situação de fragilidade e desamparo. Assim, é comum que a cirurgia mobilize, no período pré-operatório, sentimentos de incerteza, fragilidade, medo da dor, do desconhecido, de ficarem desfigurados ou sofrerem mutilações (Garanhani \& Valle, 2012; Goidanich \& Guzzo, 2012; Gomes \& Pergher, 2010).

\section{A Angústia de Castração, a Perda da Onipotência e a Ameaça de Morte}

Nesta pesquisa, verificou-se a angústia de sofrer mutilações e da marca deixada pela cirurgia. Algumas cirurgias, como a retirada da vesícula biliar ou do apêndice, envolvem uma perda real, isto é, a remoção de uma parte de si. Esse órgão, mesmo estando doente, é uma parte da criança, faz parte de sua imagem corporal e, assim, sua retirada desencadeia um processo de luto e pode alimentar fantasias mutilatórias. Além disso, a marca da cirurgia passa a ser um representante dessa perda, que o identifica como alguém que necessitou ser consertado, alguém falho, despertando angústia e vergonha de ser visto pelo outro dessa maneira. Percebe-se, também, o quanto se confrontar com esse fato foi angustiante para as crianças, que se utilizaram do riso, isto é, do humor enquanto uma defesa, fatos exemplificados pelos seguintes trechos:

O que eu tô mais com medo é (...) do tamanho. Tipo, senão eu vou ir pra escola, dai, vão ver a minha barriga, dai vão olhar o coisa. (...) Se for pequeno, tudo bem, mas eu não quero muito graaande. (mostra um corte com a mão, algo maior que sua barriga) Dai tira as tripa (ri). (HJ, P.3, Menino, 9 anos)

É que eu tô com medo que fique alguma marca, alguma coisa assim. Porque a minha mãe fez e ela tem um baita corte aqui. Não cicatrizou ainda, faz dois anos que ela já fez. (...) É que... não sei o que acontece, daí, se ela precisar cortar, ela vai ter que cortar. (HJ, P. 2, Menina, 11 anos)

Eu não sei se isso aí vai dar certo amanhã. Fico muito preocupado. (...) Então, só vou fazer que isso aqui é uma serra. Não tem que cortar esse pedaço. Não, isso aqui não deu muito certo. Deu. Já cortei. Agora eu vou martelar!"(HJ, P.6, Menino, 6 anos)

Dentro desse contexto, a situação real de cirurgia, sua marca, cicatriz, ou possível alteração do seu corpo anatômico despertam na criança a sua angústia de castração. Principalmente nos casos de tipos de cirurgia que envolvem a retirada de um órgão, pois, nesses casos, a perda não é apenas imaginada, mas concreta. Dessa forma, a marca física não fica restrita ao orgânico, ela remete também a um plano simbólico, ou seja, uma castração no sentido de uma falha e de uma perda que a marca física representa (Abel, 2011; Araújo, 2013; Lepri, 2008).

A ideia de castração, para a psicanálise, implica a perda de algo considerado muito importante para a criança (Freud, 1909/1996). Dessa maneira, várias situações 
podem ser consideradas uma castração simbólica, como separação, perda, falta e limite à onipotência do desejo (Freud, 1912-1913/1996). Assim, a cirurgia se constitui como algo que coloca limite ao sentimento de onipotência da criança e quanto maior for o valor atribuído ao órgão, maior será o sentimento de ameaça vivenciado por ela (Freud, 1908/1996).

Aberastury (1972) realizou estudo em crianças que haviam passado por intervenção cirúrgica para investigar se todo procedimento cirúrgico produziria efeitos potencialmente traumáticos. Através dessa investigação, constatou que todos os tipos de cirurgia incrementavam a angústia de castração, independentemente do sexo da criança.

Nesse estudo, percebeu-se que, apesar do assunto morte ser evitado pelas crianças, a temática estava muito presente de forma latente no conteúdo expresso. Durante a aplicação dos instrumentos, foi frequente a expressão de choque, confusão, bloqueio do canal associativo, paralisia e mobilização de agressividade frente à ameaça de morte. Assim, o assunto morte, apesar de ser evitado de forma direta, é repetido constantemente (Araújo, 2013). Além disso, todos os participantes expressaram não somente uma dificuldade relacionada à temática, mas a necessidade de defender-se da angústia do medo de morte remetendo sua ocorrência à velhice ou a uma doença grave, de modo a mantê-la afastada de si. As verbalizações a seguir estão relacionadas ao conteúdo expresso através de fábula, que oferecia como estímulo a lâmina do enterro e exemplificam as dificuldades encontradas:

Ahm... (pausa) Dá pra ti me contar de novo mais uma vez para eu entender mais? Uma amiga. Deles que tão enterrando. Deee doente. Muita dor, (pausa) eee câncer. 80 anos. Eles levando e eles indo pra casa.(TF, P.2, Menina, 11 anos)

Que mora naquela casa? É que parece uma igreja (ri). Ah que morreu naquela casa (ri). E dai disse, o homem que apontou o dedo para casa disse: 'Vamos demolir essa casa.' Para construir outra. Porque era feita de madeira e as coisas, e as coisas que tinham lá, tipo fogão, coisa, tava tudo enferrujado. Tudo que era de ferro. (TF, P.3, Menino, 9 anos)

Foi o vô ou o pai. Foi o vô. Não, foi o pai. Foi o pai. De derrame 'cerebal'al al al. Todos se sentiram muito mal. Todos morreram. Derrame 'cerebal' al al e todos viraram espííritos. Não. Que alcoviteira. (TF, P.6, Menino, 6 anos)

Como dizia Rubem Alves (1995), a única certeza que o homem tem na vida é a de que um dia morrerá. Entretanto, falar de morte se constitui em um tabu para nossa sociedade atual, que é regida pelos ideais do ter e da beleza em detrimento do ser. Freud (1912-1913/1996) considerava o medo da morte análogo à angústia de castração. Para ele, a morte se constitui numa interdição ao desejo do indivíduo, colocando limite ao narcisismo primário e à onipotência de pensamento. Assim, ela também se estabelece como uma forma de castração simbólica da criança, confrontando-a com suas fragilidades, limitações e fere suas aspirações narcisistas em seu desejo de imortalidade, configurando-se, assim, como uma ameaça (Kovács, 2005).

\section{Fantasias Atemorizantes ou Persecutórias}

Os participantes do estudo verbalizaram fantasias atemorizantes, envolvendo medos mortíferos e a percepção da necessidade de ser agredido para ser curado, ou seja, há que primeiro destruir para depois consertar. Durante HJ, um participante utilizou-se de um jogo de computador como forma de expressão do quanto o procedimento cirúrgico era agressivo e angustiante, mobilizando medos imaginários e fantasias que pareciam se confundir com a realidade, aumentando sua angústia.

Eu tenho muito nervoso. A cirurgia. A faca. Aquele negócio que eles usam pra cortar aqui. (...) Eu jogo um jogo igual. (...) Tem bisturi e martelo, pra ti quebrar os ossos. É muito louco. Tem um transplante de coração. Tu quebra tudo. Tira tudo. Tira o coração, bota outro e deixa assim. (...) Afiado. Corta fácil, só de passar assim. (...) Eu acho que é o intestino delgado. É isso? Eu sei pra passar a comida. Ah, sei lá. Eu tenho medo que o bisturi acerte na... O que tem ali mesmo que tá me dando problema? É. É uma bola, neh? Ela estoura, neh? Que nem uma bolha. E se encosta... eles vão lavar também. (HJ, P.3, Menino, 9 anos)

A aplicação do instrumento das fábulas reforçou os resultados encontrados na HJ. Os participantes evidenciaram, em comum, figuras reais ou fantasiosas, que ameaçavam com agressividade. Fato ilustrado na verbalização de dois participantes nas fábulas, que ofereciam como estímulo o medo (lâmina do medo) e a castração (lâmina do elefante), respectivamente:

Olha, ele tá com medo! Do monstro. O monstro que fica embaixo da cama. Não sei. Apavorado. É que ele olhava muito filme de terror, com monstro e por isso sonhou, dai ficou com medo. É. Eu também olho bastante filme de terror. (TF, P.4, Menino, 5 anos)

Ele estava diferente porque morreu. O ladrão matou. Se sentiu muito mal. Ele morreu! Morreu! Morreu! (TF, P.6, Menino, 6 anos)

Um dos participantes personificou seus medos e sentimento de ameaça na figura fantasiada do monstro, algo da ordem do sobrenatural, já o outro, na figura do ladrão, associando a castração à morte. De acordo com Lepri (2008), em situações extremas, como nos procedimentos cirúrgicos que envolvem uma possibilidade real de aniquilamento do ego, as fantasias são alimentadas pelo medo e pela angústia da criança, quando essa não se sente em condições de lidar com a situação. Ainda de acordo com a autora, o adoecimento e a cirurgia podem ser vistos pela criança como uma retaliação ou uma punição por parte das figuras 
parentais, nutrindo fantasias persecutórias advindas dos impulsos destrutivos contra eles.

As fantasias de caráter atemorizante ou persecutório geralmente se apresentam em situações em que os adultos omitem informações a respeito do processo cirúrgico. Esse fato está relacionado principalmente a duas circunstâncias: uma situação é crença culturalmente difundida, de que as crianças nem sempre são capazes de entender os motivos reais e a complexidade que envolve um procedimento cirúrgico; Já a outra, está associada à dificuldade dos pais em falar com a criança sobre a necessidade do procedimento, por vezes, omitindo informações ou enganando a criança. Entretanto, contrariamente à crença culturalmente difundida, a criança tem grande capacidade de observação e percebe que algo diferente ocorre, bem como sente a dificuldade da família para lidar com o processo. Assim, pode despertar na criança uma sensação de que os pais e a equipe estão premeditando algo contra ela (Finkel \& Espíndola 2008; Garanhani \& Valle, 2012; Mikowski, 2008). Dessa maneira, possibilitando acarretar um processo regressivo na criança, com o acionamento de mecanismos de defesa primários, mobilizados pela reativação de medos primitivos infantis (Garanhani \& Valle, 2012; Hearst, 2009; Lepri, 2008). Além disso, quando os pais tentam esconder ou evitar falar sobre a condição da criança com ela, acabam intensificado seus medos e angústias (Lepri, 2008).

\section{A Identificação com o Agressor e a Ambivalência Atribuída à Figura do Médico}

Percebeu-se que a maioria dos sujeitos desta pesquisa, frente à angústia elevada, mobilizada por fantasias persecutórias em relação ao procedimento cirúrgico, utilizou, frequentemente, a identificação com o agressor como um recurso defensivo. Seis participantes, através de seu discurso e do conteúdo expresso durante o TF, apresentaram o mecanismo de defesa da identificação com o agressor. A seguir, exemplificado pelo discurso dos participantes expresso durante $\mathrm{HJ}$ :

Tem que cobrir os ferimentos. Nos braços. Vou precisar disso para não sentir dor. Tem que pegar e ver os batimentos cardíaco. Precisa de repouso. Precisa de remédio. (...) Salvando mais uma pessoa. Tem que procurar um ferido. Embaixo das pedras dum barranco. Tem que levar ele até o hospital. No pé. Ta machucado. É para ele não sentir dor. (HJ, P.5, Menino, 12 anos)

Eu acho que é um coisa de abastecer as pessoas, com agulha uma coisa. (...)Eu vou te colocar o oxigênio e tu fica. (...) Só deixa eu arrumar em ti. Deixa eu ver a agulha. (...) É oxigênio. Esse tipo de oxigênio a gente se usa. Fazer esse tipo que tu precisa. Tu veio botar esse oxigênio. Entendeu? (...) Abre a boca! Porque sim. Porque tem que ser. (...) É uma bombinha de falta de ar. (HJ, P.6, Menino, 6 anos)
Levando-se em consideração toda ambivalência presente no ato cirúrgico e a expressão de fantasias persecutórias pela criança, é comum que essas, em sua imaginação, busquem se identificar com o agressor, na tentativa de compreender e se defender daquilo que a cirurgia mobiliza. Anna Freud (1946/1968), em seu livro O ego e os mecanismos de defesa, caracterizou o mecanismo de defesa de identificação com o agressor pela combinação de duas defesas: a introjeção e a projeção. Através disso, o ego buscaria dominar a ansiedade, se identificando com o afeto, isto é, a agressividade e projetando o sentimento de culpa. Assim, através da troca de papéis durante a brincadeira, a criança poderia ocupar, ao mesmo tempo, o papel de vítima e de agressor, ou seja, passivo e ativo, livrando-se do desprazer do abandono e de se encontrar em posição vulnerável de ser agredida por um adulto.

Ferenczi (1933/1992), por sua vez, acrescentou ao conceito a ideia de que esse mecanismo estaria relacionado a um trauma inassimilável, que seria fruto de uma falha do ambiente exterior. Essa falha seria originária de uma incapacidade do adulto em compreender as reais necessidades da criança, que são interpretadas de acordo com a sua realidade pessoal. Outro conceito importante do autor é o de Desmentido. O desmentido corresponderia ao momento em que a criança desamparada buscou o apoio do adulto para conferir sentido à experiência traumática, entretanto, esse foi incapaz de dar conta do traumático e acaba tomando a palavra da criança como uma mentira ou algo fantasioso. Assim, o desmentido pode conferir a essa experiência traumática um caráter intensamente desestruturante e patológico, já que a criança busca se organizar psiquicamente através dos sentidos que lhes são conferidos pelos adultos (Fuchs \& Júnior, 2014).

Ao aplicarem-se esses conceitos à situação pré-cirúrgica e às fantasias mobilizadas pela operação na criança, o desmentido traumático poderia ser comparado à dificuldade dos pais e profissionais da saúde em falar com a criança sobre a cirurgia. Assim, os pais, na intenção de protegê-la de sentimentos de angústia, frente a sua própria, tornar-se-iam incapazes de escutar e de acolher as angústias e fantasias despertadas pela cirurgia. Esse fato transmitiria à criança a mensagem de que o assunto é proibido, impedindo qualquer possibilidade de significação e simbolização.

Ainda na via de entendimento da defesa através do mecanismo de identificação com o agressor, a criança identifica-se com ele para não perder o objeto idealizado. Assim, a raiva que a criança sentiria da agressão e do agressor é redirecionada para ela mesma, sentindo-se culpada pela situação e, assim, não precisa abrir mão do adulto idealizado e consegue dominar o sofrimento de ser objeto de agressão (Fuchs \& Júnior, 2014).

Verificou-se também, nos participantes, uma ambivalência importante em face da figura do médico, que ora é visto de maneira idealizada, ora como agressor. Alguns participantes expressaram a percepção de que seus pais não poderiam lhes 
ajudar, sendo necessário um terceiro, uma figura de poder, um representante paterno representado pelo médico. Um menino, relatando uma estória desencadeada pela lâmina do passarinho, expressou sua percepção da necessidade de um terceiro que pudesse realizar o conserto, como pode se compreender no seguinte trecho:

Essas árvores ficam num parque. Uma certa pessoa que chega no parque de manhã para ver a manutenção e coisa e tal. Vê o ninho, pega o ninho e põe na árvore de volta. O gerente do parque. Depois que ele salvou os filhotes. Eles continuaram vivendo a sua vida (...). (TF, P.1, Menino, 12 anos)

Também se percebeu a estratégia de idealização da figura do médico. No depoimento a seguir, pode-se inferir que o participante demonstrou não só ter a visão da figura do médico que ajuda, mas também como um profissional que se preocupa com seus pacientes, mesmo fora do expediente e que mantém relação próxima a esses:

Ai, como eu estou se estressando com essa causa de doença da Kely! Eu posso ligar para ela para ela vir consultar de volta se ela quiser ou se ela não melhorou. (...) Oi. Você pode vir consultar hoje a minha volta? Você está melhor? Pode ser qualquer hora. Eu espero você. (...) Ai, ainda bem que ela está melhor. Não aguentava mais assim. Ela podia estar muito ruim. Ainda bem que ela melhorou. (HJ, P.7, Menina, 9 anos)
Já outros dois participantes expressaram sua percepção da figura do médico enquanto um agressor, assim, direcionando os sentimentos de ameaça e agressividade a ele. Através de seu desenho (Figura 1) e seu discurso, um dos participantes aparentava expressar que aquele que detém o falo, o poder, é o cirurgião. Esse falo é destrutivo e cortante como uma flecha, podendo matar. Pode-se averiguar que o cirurgião assumiu, para essa criança, as características de uma figura que parte era homem, parte animal: "Uma flecha. Não sei. É um lobisomem. Ele vai matar os bichos. Os bichos" (HJ, P.4, Menino, 5 anos).

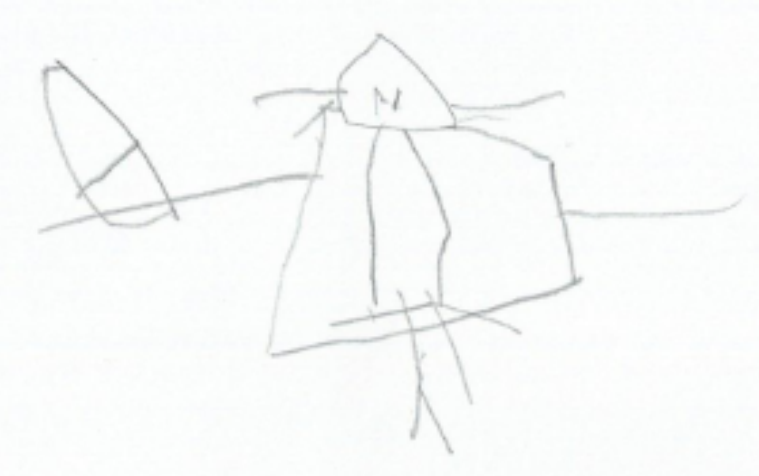

Figura 1. O lobisomem e a flecha para matar os animais (HJ, P.4, Menino, 5 anos).

\section{DISCUSSÃO}

A fantasia não é um sintoma. Ela é originária ou constituinte do sujeito (D'Agord, Triska, Araldi, \& Sudbrack, 2010). O fantasiar da criança, não somente em relação ao procedimento cirúrgico, mas também em relação às causas de seu adoecimento, é normal e natural, fazendo parte do processo de elaboração psicológica, isto é, atribuição de sentido a uma situação ou experiência (Araújo, 2013; Colombi, 2010; Lepri, 2008), ainda mais no caso da cirurgia, que é um procedimento agressivo e que carrega a ameaça de uma aniquilação real e de uma perda concreta, despertando na criança a ideia de ser atacada e dominada (Gabarra \& Crepaldi, 2009; Lepri, 2008; Prudenciatti et al., 2013). Esses fatos tornam mais difícil a atribuição de um sentido ao processo cirúrgico. Dessa maneira, a fantasia funcionaria como uma defesa contra a "castração real" mobilizada pela cirurgia, de forma a conter a castração imaginária, suspendendo-a momentaneamente e realizando um ocultamento do real traumático (Araújo, 2013).

O conceito de trauma de Freud (1920/1996), em Além do principio do prazer, implica numa ruptura no escudo que protege o aparelho psíquico, quando esse é submetido a excitações muito intensas, as quais não consegue conter. Essa excitação abrasadora seria responsável pela suspensão momentânea do princípio do prazer devido à necessidade de reorganização do aparelho psíquico, de forma a atribuir significação à experiência traumática. De acordo com ele, isso seria possível pela existência de uma tendência mais primitiva no aparelho psíquico, a pulsão de morte. Essa tendência de dominar uma experiência através de sua transformação, de uma ação passiva para uma ativa, seria anterior à dominância do princípio do prazer e independente dele. Enquanto o princípio do prazer evita o desprazer, a pulsão de morte repete constantemente o momento de desprazer, vivenciado na tentativa de controlá-lo. Desse modo, o aparelho psíquico desenvolve a angústia que prepara o sujeito para o perigo e que não foi gerada anteriormente, ocasionando o trauma, procurando dominar a situação traumática através das repetições.

Percebeu-se que, através da brincadeira, os sujeitos dessa pesquisa tentavam compreender a necessidade da cirurgia e estabelecer um significado a essa. Nessa via de entendimento, compreende-se o brincar e as fantasias como funções criativas, elaborativas e preparatórias ao ato cirúrgico, conforme observado no relato dos participantes. Pode-se verificar que, a partir da brincadeira, literalmente foi possível que os participantes consertassem ou construíssem algo, mesmo a partir de um ato violento. Assim, eles demonstraram atribuir significação para o ato cirúrgico, tão ambivalente, agressivo e destrutivo, mas necessário à cura, ao alívio do sofrimento e à sobrevivência. 
No contexto pré-operatório, ao brincar e desenhar, a criança dá vazão à sua realidade psíquica, seu mundo de fantasias e pode externalizar seus temores e angústias. Dessa maneira, as fantasias podem assumir, também, um caráter preparatório ao procedimento cirúrgico. $\mathrm{O}$ brincar de médico possibilita substituir a situação real pelo imaginário e permite à criança identificar e lidar de forma simbólica com aquilo que a cirurgia lhe representa (Lerwick, 2013; Prudenciatti et al., 2013). Abd-Elsayed, Delgado e Livingstone (2013) realizaram um estudo que investigou, por meio do desenho, a percepção da autoimagem de crianças com deformidade antes da realização da cirurgia. Esses autores constataram que todas as crianças se desenharam sem nenhuma deformação e concluíram que os resultados sugeriam que, através do desenho, elas tentavam compensar sua deficiência, pelo uso construtivo da fantasia.

Existe, no hospital, a crença difundida não somente pelo senso comum, mas também por alguns trabalhos como Costa, Silva e Lima (2012), Martínez, León, Rodríguez e Moctezuma (2010), Prudenciatti et al. (2013), de que as fantasias, por serem consideradas uma defesa primitiva, dificultariam o período pós-operatório. Esses autores defendem a ideia de que elas reforçariam quadros de angústia e ansiedade frente ao processo cirúrgico. Certamente as fantasias podem influenciar nas atitudes e recuperação dos pacientes, pois podem se converter num meio de defesa contra a ansiedade mobilizada pela cirurgia, como forma de diminuir a sua tensão (Finkel \& Espíndola, 2008; Prudenciatti et al., 2013; Velázquez et al., 2005). Entretanto, segundo um referencial teórico psicanalítico, é atribuído à fantasia um papel paradoxal. Assim, mesmo a fantasia se constituindo em uma defesa regressiva, ela é considerada uma estrutura protetora, que auxilia na sublimação, constituindo-se em defesa momentânea à castração real imposta pelo ato cirúrgico (Abel, 2011; Araújo, 2013).

Além disso, ao se abordar a temática da fantasia, é importante ter em mente que elas estão relacionadas à realidade psíquica do sujeito, isto é, para ele é a sua versão da realidade, além de ser sua realidade interna (Abel, 2011; Ogden, 2011). Por meio da fantasia, ele pode atribuir um significado para sua história e até mesmo alterá-la, de forma a assumir um papel ativo perante um evento que teria que vivenciar passivamente (Abel, 2011; Lepri, 2008).

\section{CONSIDERAÇÕES FINAIS}

Independentemente de a criança já ter vivenciado uma cirurgia antes, da sua idade ou da complexidade do procedimento, a operação a coloca em situação de fragilidade e desamparo, mobilizando sentimentos de solidão, tristeza, confusão e diversos medos. O procedimento cirúrgico é marcado pela ambivalência de que, para ser curada, a criança deve ser agredida. Na linguagem infantil, para ela ser consertada, deve primeiro ser quebrada, fato que remete ao medo do aniquilamento e da morte, bem como a uma dificuldade em lidar com a morte.

Do mesmo modo, foi possível identificar a presença de fantasias em relação ao adoecimento, fantasias atemorizantes e fantasias elaborativas, quanto ao procedimento cirúrgico em momento anterior à realização da cirurgia. Os resultados sugeriram existir uma ligação entre a presença das fantasias pré-cirúrgicas e o mecanismo de defesa da identificação com o agressor, pelo seu caráter traumático e o fato de ser desmentido pelo adulto. Evidenciou-se, também, nesse sentido, a importância de transmitir informações à criança sobre o processo cirúrgico, evitando, assim, que fantasias persecutórias venham preencher lacunas a respeito do procedimento cirúrgico.

Portanto, frente a tais proposições, faz-se relevante desmistificar a ideia presente na instituição hospitalar da fantasia como algo prejudicial ao processo cirúrgico. Essa visão difundida pode reforçar estereótipos, rotulações e gerar falsas expectativas frente à equipe, como se houvesse uma "receita" única de como lidar e trabalhar com a fantasia. É necessário avaliar cada caso em sua singularidade no momento em que é identificada a necessidade do procedimento cirúrgico. Nesse momento, também é possível realizar a avaliação psicológica da criança e planejar se haverá ou não a necessidade de acompanhamento psicológico e como esse se dará. A presença de um psicólogo durante o processo pode identificar as necessidades de cada caso e em quais deles a fantasia se constitui como algo prejudicial, de forma a realizar um trabalho preventivo. $\mathrm{O}$ psicólogo pode auxiliar a criança a lidar com as fantasias persecutórias mobilizadas pela ameaça de morte e pelo despertar de medos primitivos, conferindo, através da escuta, valor e significado ao seu discurso verbal e não verbal, bem como a suas vivências.

Neste estudo, através da associação da HJ e do TF como instrumentos de pesquisa, foi possível acessar ampla gama de dados. Essas ferramentas possibilitaram aos participantes expressar com maior facilidade suas percepções e angústias mobilizadas pela iminência da realização de um procedimento cirúrgico. Entretanto, levando-se em conta a complexidade do conceito de fantasia e o papel que ela assume frente à realização de uma cirurgia, sugere-se a realização de outros estudos que investiguem as fantasias dentro de contextos específico, bem como a utilização de outros métodos de pesquisa. 


\section{REFERÊNCIAS}

Abd-Elsayed, A. A., Delgado, S. V., \& Livingstone, M. (2013). Self-image perception of 171 children and adolescents with cleft lip and palate from 22 countries. The Ochsner Journal, 13(2), 204-207. Recuperado de https://europepmc.org/articles/ PMC3684329

Abel, M. C. (2011). Verdade e fantasia em Freud. Ágora, 14(1), 47-60. http://dx.doi.org/10.1590/S1516-14982011000100004

Aberastury, A. (1972). Historia de una tecnica: Preparacion psicoterapeutica en cirurgia. In A. Aberastury, El psicoanalisis de ninños y sus aplicaciones (pp. 34-43). México: Paidos.

Aberastury, A. (1992). Psicanálise da Criança: Teoria e técnica. Porto Alegre: Artmed. (Trabalho original publicado em 1982)

Alves, R. (1995). Sobre o tempo e a eternidade. Campinas: Papirus.

Araújo, F. M. (2013). O véu do inconsciente e a questão da angústia. Cadernos de Psicanálise, 35(28), 149-168. Recuperado de http://pepsic.bvsalud.org/scielo.php?script=sci arttext\&pid=S1413-62952013000100009\&lng=pt\&tlng=pt.

Bardin, L. (2010). Análise de Conteúdo. Lisboa: Ed. 70. (Trabalho original publicado em 1977)

Brasil. (1990). Lei $n^{\circ} 8.069$, de 13 de julho de 1990. Estatuto da Criança e do Adolescente. Recuperado de: http://www.planalto. gov.br/ccivil 03/leis/18069.htm

Brasil. (2012). Resolução $n^{\circ} 466$, de 12 de dezembro de 2012. Diretrizes e normas regulamentadoras de pesquisas envolvendo seres humanos. Recuperado de http://conselho. saude.gov.br/resolucoes/2012/Reso466.pdf

Colombi, L. (2010). The dual aspect of fantasy: Flight from reality or imaginative realm? Considerations and hypotheses from clinical psychoanalysis. The International Journal of Psychoanalysis, 91(5), 1073-1091. doi: 10.1111/j.17458315.2010.00327.x

Conselho Federal de Psicologia. (2000). Resolução CFP 016/2000. Dispõe sobre a realização de pesquisas em psicologia com seres humanos. Recuperado de http://www.crpsp.org.br/portal/ orientacao/resolucoes_cfp/fr_cfp_016-00.aspx

Costa, V. A. de S. F., Silva, S. C. F., \& Lima, V. C. P. (2012). O pré-operatório e a ansiedade do paciente: A aliança entre o enfermeiro e o psicólogo. Revista da Sociedade Brasileira de Psicologia Hospitalar, 13(2), 282-298. Recuperado de http:// pepsic.bvsalud.org/pdf/rsbph/v13n2/v13n2a10.pdf

Cunha, J. A., \& Nunes, M. L. T. (1993). Teste das Fábulas: Forma verbal e pictórica. São Paulo: Centro Editor de Testes e Pesquisas em Psicologia.

D'Agord, M. R. de L., Triska, V. H. C., Araldi, E., \& Sudbrack, R. P. (2010). Psicanálise, psicopatologia e literatura: Modos de uso da fantasia. Tempo Psicanalitico, 42(2), 313-332. Recuperado de http://pepsic.bvsalud.org/pdf/tpsi/v42n2/v42n2a04.pdf

DeMaso, D. R., \& Snell, C. (2013). Promoting coping in children facing pediatric surgery. Seminars in Pediatric Surgery, 22(3), 134-138. http://dx.doi.org/10.1053/j.sempedsurg.2013.04.004

Dolto, F. (2008). A imagem inconsciente do corpo. São Paulo: Perspectiva. (Trabalho original publicado em 1984)

Ferenczi, S. (1992). Confusão de línguas entre os adultos e a criança. In S. Ferenczi, Obras completas: Psicanálise IV (A. Cabral, trad., Vol. 4, pp. 97-106) São Paulo: Martins Fontes. (Trabalho original publicado em: 1933)

Ferreira, F. R. (2008). A produção de sentidos sobre a imagem do corpo. Interface - Comunicação, Saúde, Educação, 12(26), 471-83. Recuperado de https://www.scielosp.org/pdf/ icse/2008.v12n26/471-483/pt

Finkel, L. A., \& Espíndola, V. B. P. (2008). Cirurgia cardíaca pediátrica: O papel do psicólogo na equipe de saúde. Psicologia para América Latina, 13. Recuperado de http://pepsic.bvsalud. org/scielo.php?script=sci_arttext\&pid=S1870-350X20080002 $00004 \& \operatorname{lng}=$ pt\&nrm=iso\&tlng $=\mathrm{pt}$

Fontanella, B. J. B., Ricas, J., \& Turato, E. R. (2008). Amostragem por saturação em pesquisas qualitativas em saúde: Contribuições teóricas. Cadernos de Saúde Pública, 24(1), 17-27. Recuperado de https://www.scielosp.org/pdf/csp/2008.v24n1/17-27/pt

Freud, A. (1968). Identificação com o agressor. In A. Freud, $O$ ego e os mecanismos de defesa (pp. 121-133). Rio de Janeiro: Biblioteca Universal Popular. (Trabalho original publicado em 1946)

Freud, S. (1996). Sobre as teorias sexuais das crianças. In S. Freud, Edição Standard das obras psicológicas completas de Sigmund Freud (J. Salomão, trad., Vol. 9, pp. 189-204). Rio de Janeiro: Editora Imago. (Trabalho original publicado em 1908)

Freud, S. (1996). Análise de uma fobia de um menino de cinco anos. In S. Freud, Edição Standard das obras psicológicas completas de Sigmund Freud (J. Salomão, trad., Vol. 10, pp. 13-133). Rio de Janeiro: Editora Imago. (Trabalho original publicado em 1909)

Freud, S. (1996). Totem e tabu. In S. Freud, Edição Standard das obras psicológicas completas de Sigmund Freud (J. Salomão, trad., Vol. 13, pp. 13-163). Rio de Janeiro: Editora Imago. (Trabalho original publicado em 1912-1913)

Freud, S. (1996). Além do Princípio do Prazer. In S. Freud, Edição Standard das obras psicológicas completas de Sigmund Freud (J. Salomão, trad., Vol. 18, pp. 13-75). Rio de Janeiro: Editora Imago. (Trabalho original publicado em 1920)

Fuchs, S. M. S., \& Júnior, C. A. P. (2014). Sobre o trauma: Contribuições de Ferenczi e Winnicott para a clínica psicanalítica. Tempo Psicanalítico, 46(1), 161-183. Recuperado de http://204.16.6.99/index.php/tempopsicanalitico/article/ viewFile/13/pdf_11

Gabarra, L. M., \& Crepaldi, M. A. (2009). Aspectos psicológicos da cirurgia de amputação. Aletheia, 30, 59-72. Recuperado de http:// pepsic.bvsalud.org/scielo.php?script=sci_arttext\&pid=S141303942009000200006\&lng=pt\&tlng $=$.

Garanhani, M. L., \& Valle, E. R. M. (2012). O significado da experiência cirúrgica para a criança. Ciência Cuidado e Saúde, 11(5), 259-266. doi: 10.4025/cienccuidsaude.v10i5.17084

Goidanich, M., \& Guzzo, F. (2012). Concepções de vida e sentimentos vivenciados por pacientes frente ao processo de Hospitalização: O Paciente Cirúrgico. Revista da Sociedade Brasileira de Psicologia Hospitalar, 15(1), 232-248. Recuperado de http://pepsic.bvsalud.org/pdf/rsbph/v15n1/ v15n1a13.pdf

Gomes, J. A. da L., \& Pergher, G.K. (2010). A TCC no pré e pós operatório de cirurgia cardiovascular. Revista Brasileira de Terapias Cognitivas, 6(1), 173-194. doi: 10.5935/18085687.20100010

Hearst, D. (2009). The runaway child: Managing anticipatory fear, resistance and distress in children undergoing surgery. Pediatric Anesthesia, 19, 1014-1016. doi:10.1111/j.14609592.2009.03146.x

Kovács, M. J. (2005). Educação para Morte. Psicologia: Ciência e Profissão, 25(3), 484-497. Recuperado de https://dialnet. unirioja.es/servlet/articulo?codigo $=5984008$

Lepri, P. M. F. (2008). A criança e a doença: Da fantasia à realidade. Revista da Sociedade Brasileira de Psicologia Hospitalar, 11(2), 15-26. Recuperado de http://pepsic.bvsalud.org/scielo. php?script $=$ sci_arttext\&pid $=$ S1516-08582008000200003\&ln $\mathrm{g}=\mathrm{pt} \& \mathrm{t} \operatorname{lng}=\mathrm{pt}$. 
Lerwick, J. L. (2013). Psychosocial implications of pediatric surgical hospitalization. Seminars in Pediatric Surgery, 22, 129-133. https://doi.org/10.1053/j.sempedsurg.2013.04.003

Martínez, B. P. R., León, E. C., Rodríguez, G. A. R., \& Moctezuma, L. G. P. (2010). Defense mechanisms in cardiovascular disease patients with and without panic disorder. Salud Mental, 33(3), 219-227. Recuperado de http://www.medigraphic.com/pdfs/ salmen/sam-2010/sam103b.pdf

Mikowski, E. M. P. (2008). Intervenção psicológica em crianças a serem submetidas à cirurgia através do brinquedo terapêutico diretivo (Monografia não publicada). Universidade Federal de Sergipe, São Cristóvão. Recuperado de http://newpsi.bvs-psi. org.br/tcc/EstherMikowski.pdf

Ogden, T. H. (2011). Reading Susan Isaacs: Toward a radically revised theory of thinking. The International Journal of Psychoanalysis, 92(4), 925-942. doi: 10.1111/j.17458315.2011.00413.x

Prudenciatti, S. M., Tavano, L. D. A., \& Neme, C. M. B. (2013). O Desenho - Estória na atenção psicológica a crianças na fase pré-cirúrgica. Boletim-Academia Paulista de Psicologia, 33(85), 276-291. Recuperado de http:// pepsic.bvsalud.org/pdf/bapp/v33n85/a06.pdf

Torres-Oquendo, F., \& Toro-Alfonso, J. (2012). Las representaciones corporales: Una propuesta de estudio desde una perspectiva compleja. Eureka, 9(1), 88-97. Recuperado de http://pepsic. bvsalud.org/scielo.php?script $=$ sci_arttext\&pid $=\mathrm{S} 2220$ 90262012000100010\&lng=pt\&tlng=es.
Turato, E. R. (2003). Tratado da metodologia da pesquisa clínicoqualitativa: Construção teórico-epistemológica, discussão comparada e aplicação nas áreas da saúde e humanas. Petrópolis: Vozes.

Velázquez, M. E. R., Dearmas, A., Sauto, S., Techera, S., Perillo, P., Suárez, A., \& Berazategui, R. (2005). Trabajo de investigación en psicoprofilaxis quirúrgica pediátrica. Primera experiencia nacional. Archivos de Pediatría del Uruguay, 76(1), 27-37. Recuperado de http://www.scielo.edu.uy/scielo. php?script $=$ sci_arttext\&pid $=$ S1688-12492005000100006\&ln $\mathrm{g}=$ es\&tlng=es

Winnicott, D.W. (2008). A criança e o seu mundo. Rio de Janeiro: LTC Editora. (Trabalho original publicado em 1982)

Submetido: 02/07/2015

Aceito: $12 / 01 / 2018$ 